\title{
Effects of glycerol and nanoclay on physiochemical properties of camelina gum-based films
}

\author{
Guangyan $\mathrm{Qi}^{\mathrm{a}}$, Ningbo Li ${ }^{\mathrm{b}}$, Xiuzhi Susan Sun ${ }^{\mathrm{a}}$, Yong-chen Shi ${ }^{\mathrm{a}}$, Donghai Wang ${ }^{\mathrm{c}, *}$ \\ ${ }^{a}$ Department of Grain Science and Industry, Kansas State University, Manhattan, KS 66506. \\ ${ }^{\mathrm{b}}$ Sunhai Bioadhesive Technologies LLC, Manhattan, KS 66502. \\ ${ }^{\mathrm{c}}$ Department of Biological and Agricultural Engineering, Kansas State University, Manhattan, KS \\ 66506. \\ *Corresponding author. Tel: 785-532-2919. Fax: 785-532-5825.Email: dwang@ksu.edu \\ (Donghai Wang)
}




\begin{abstract}
Film-forming properties of camelina gum (CG) were evaluated, including film appearance and morphological, mechanical, water/light barrier, and thermal properties. With $4 \%$ nanoclay, tensile strength of film increased from 43.2 $\mathrm{MPa}$ to 54.6 MPa without change elongation property. The formation of physically cross-linked networks in the film increased interfacial affinity between the CG matrix and intercalated nanoclay, as proved by FTIR and X-ray diffraction (XRD) data, which contributed to the mechanical strength of film. The increased nanoclay level $(6 \%-10 \%)$ resulted in limited mechanical strength improvement due to poor dispersion and the appearance of agglomerates of nanoclay in the film matrix, as shown in morphological study. The compact structure of CG/nanoclay film could reduce the free volume of film matrix and obstruct the diffusion of water, thereby decreasing the water vapor permeability. The ultraviolet (UV) light transmittance of CG film decreased by $40 \%$ with $10 \%$ nanoclay.
\end{abstract}

Keywords: Camelina gum, Nanoclay, Film 


\section{Introduction}

Health and environmental concerns as well as high demand for extended shelf life have motivated the development of edible films, thin layers that can be served as barriers between food components or between food and the surrounding environment, or function as carriers for food additives, antioxidants, antimicrobial agents, and nutrients (Talens et al., 2010). Appropriate materials for making edible films include polysaccharides, proteins, lipids, and the combinations of those materials (Sothornvit \& Krochta, 2000). The use of polysaccharides, such as starches and their derivatives, cellulose, and gums for edible films has been increasing because of their abundantness and properties that may be improved by chemical modifications (Phan et al., 2002). Polysaccharide-based film forms when gum solutions are casted on a surface and then dried at a certain temperature and humidity level, consequently demonstrating plasticity, tensile strength (TS), and clarity characteristics. Film properties vary depending upon gum properties. In previous studies, linear polysaccharides, such as agar, curdlan, hydroxypropyl methylcellulose (HPMC), and gellan-based films, which all have methyl, hydroxypropyl, acyl, or acetyl substituents covalently attached to their individual sugar molecules, showed optimum film-forming property with good mechanical strength (Murray, 2000; Labropoulos et al., 2002). As opposed to linear polysaccharides, branched polysaccharides, however, have very large molecular weights with globular conformation, but this molecular structure does not allow the formation of micelles consisting of intimately associated polymer chains, resulting in poor film-forming properties as evidenced by gum arabic, gum ghatti, and gum karaya-based films (Embuscado \& Huber, 2009).

Properties of polysaccharide-based films can be manipulated through plasticization or physicochemical modification. Plasticizers with low molecular weight are widely used to soften the rigid structure and improve the processing, mechanical, barrier, and physical properties of films. 
Most-favored plasticizers are compatible with film-forming polymers and can reduce intermolecular forces and increase the free volume or mobility of polymer chains by reducing hydrogen bonding between polymer chains. Examples of such plasticizers include glycerol, sorbitol, and polyethylene glycol (Gontard et al., 1993). Efforts also have been made to improve the physical properties of polysaccharide film by reinforcing the polymer matrix with layered clay minerals, such as environmentally friendly, nontoxic, abundant montmorillonite (MMT) (Alexandre \& Dubois, 2000). Nanoscale distribution of nanoclay with high aspect ratio and high surface-to-volume ratio in the gum matrix (agar, carrageenan, arga/carrageenan/konjac glucomannan, carrageenan/locust bean) improved the mechanical, thermal, and barrier properties of films with low filler content (less than 5\% of gums by weight) (Rhim \& Hong, 2011; Martins et al., 2013; Rhim \& Wang, 2013; Rhim \& Wang, 2014). Therefore, nanoclays significantly improve the feasibility of gum-based films in food packaging application.

CG extracted from camelina seed has shown excellent viscoelastic property and has the potential for use as a thickener, suspending agent, and stabilizer (Li et al., 2016). We speculate that those properties of CG may attribute its film forming properties. Little to no research information is available regarding to CG-based films. Therefore, the objective of this research was to investigate CG film-forming properties as affected by plasticizer (glycerol) and nanoclay. Nano clay can be modified through exchanging of hydrated cations with organic modifiers such as alkylammonium cations etc (Ruiz-Hitzky et al., 2010). The modified clay known as organo clay with the increased hydrophobicity was used in this study. We expected that the increased hydrophobicity might be better for improving water vapor permeability of gum film besides the mechanical and UV barrier properties etc. The clay modified CG films were characterized using FTIR, XRD, SEM, atomic force microscopy (AFM), and thermal gravimetric analysis (TGA) 
analysis. Transparency, moisture content, water vapor permeability, thickness, and mechanical properties of films were also evaluated.

\section{Materials and methods}

\subsection{Materials}

CG consisting of polysaccharides (75.1\%) and protein (12.3\%) (Li et al., 2016) was provided by Sunhai Bioadhesive Technologies LLC (Manhattan, Kansas, United States). Nanoclay of MMT organoclay modified by quanternary ammonium salts (methyl dihydroxyethyl hydrogenated tallow) and glycerol (99.5\%) were purchased from Sigma Aldrich (St. Louis, Missouri, United States).

\subsection{Film Preparation}

CG film was prepared using a solution-casting method. A $0.5 \%$ CG gum solution was prepared by adding $0.35 \mathrm{~g}$ of camelina powder $(<0.25 \mathrm{~mm})$ to $70 \mathrm{ml}$ distilled water with $30 \%-70 \%$ glycerol (w/w, dry basis) as a plasticizer. The mixture was stirred vigorously with a magnetic stirrer for approximately $30 \mathrm{~min}$ at $25{ }^{\circ} \mathrm{C}$ and then casted evenly onto leveled polystyrene petri dishes $(15$ $\mathrm{mm}$ diameter) and dried for $17 \mathrm{~h}$ at $50{ }^{\circ} \mathrm{C}$.

$\mathrm{CG} /$ nanoclay films were prepared using a solution intercalation method. Nanoclay was used at five levels: $1 \%, 2 \%, 4 \%, 8 \%$, and $10 \%$ (w/w, dry basis). The method described by Martin et al. (2013) was used. Nanoclay powder was dispersed into distilled water under magnetic stirring for $24 \mathrm{~h}$ for hydration. CG powder was then dissolved into the nanoclay solution after adding glycerol $(50 \% \mathrm{w} / \mathrm{w}$, dry basis). The suspension was sonicated for $30 \mathrm{~min}$. using an ultrasonic machine (model AP-1000, Sonic-Mill, Albuquerque, New Mexico, United States) and then heated for 30 min. at $70{ }^{\circ} \mathrm{C}$ in a water bath. Film-forming solutions were degassed under vacuum to remove dissolved air bubbles, and then $70 \mathrm{ml}$ solution was cast onto the petri dishes (15 $\mathrm{mm}$ diameter) and 
the same procedures were followed as described for CG film preparation. Obtained films were conditioned at $50 \%$ relative humidity $(\mathrm{RH})$ and $25{ }^{\circ} \mathrm{C}$ for at least 3 days in a controlled environmental chamber (Electro-Tech Systems, Inc., Glenside, Pennsylvania, United States) for further analysis.

\subsection{Film Morphology}

\section{Scanning Electron Microscopy}

A Hitachi S-3500 N (Hitachi Science System, Ibaraki, Japan) scanning electron microscopy (SEM) was used to observe the microstructure of the gum films. Films were affixed to an aluminum stub with two-sided adhesive tape, and a sputter coater was used to coat the films with an alloy of $60 \%$ gold and $40 \%$ palladium (Desk IIS putter/Etch Unit, Moorestown, New Jersey, United States). SEM images of samples were obtained at an operation condition with an accelerating voltage of $5 \mathrm{kV}$.

\section{Atomic Force Microscopy}

Surface morphology of the films was analyzed using an Innova AFM (Bruker Nano Surfaces Division, Texas, United States). After equilibration at 53\% RH for $48 \mathrm{~h}$, samples were cut into thin pieces that fit into the AFM image sample holder; the samples were then affixed to double-sided tape. Film samples were scanned in contact mode using a Burker's sharp nitride lever (SNL) probe, which combines the sharpness of a silicon tip with a low spring constant of $0.12 \mathrm{~N} / \mathrm{m}$ and a nominal tip radius of approximately $2 \mathrm{~nm}$. Experiments were carried out in air at a scan rate of $2 \mathrm{~Hz}$, and a vertical deflection of $2 \mathrm{~V}$ was applied. All AFM images with $512 \times 512$ pixels were obtained.

\subsection{Fourier Transform Infrared Spectroscopy}

A PerkinElmer Spectrum 400 FT-IR/FT-NIR spectrophotometer (Shelton, Connecticut, United States) was used to collect FTIR spectra of gum films in the region of $400-4000 \mathrm{~cm}^{-1}$. Transmission 
spectra of 32 scans of each sample were collected at a resolution of $1 \mathrm{~cm}^{-1}$ in the reflectance mode. All samples were tested with duplications.

\subsection{XRD Analysis}

XRD patterns of the film samples were analyzed using an EMPYREAN X-ray diffractometer (PANalytical, Westborough, Massachusetts, United States) operated at 40kV and $30 \mathrm{~mA}$. Samples were prepared by placing a rectangular film $(2 \times 3 \mathrm{~cm})$ on a glass slide, and spectra were recorded using $\mathrm{Cu}-\mathrm{Ka}$ radiation at a wavelength of $0.154 \mathrm{~nm}$. All experiments were carried out from $4^{\circ}$ to $50^{\circ}$ (2 $\theta$ range) with a step interval of $0.007^{\circ}$. Interlayer spacing of the films containing the nanoclays was determined by the XRD peak using Bragg's equation $(\lambda=2 d \sin \theta)$, where $\lambda$ corresponds to the wavelength of X-ray radiation $(0.154 \mathrm{~nm}), d$ corresponds to interlayer spacing between diffraction lattice planes, and $\theta$ is the measured diffraction angle of the peak in the XRD pattern.

\subsection{Mechanical properties}

The TS and percentage of elongation at break $(\mathrm{Eb}, \%)$ were measured with a tensile tester (TT1100, ChemInstruments, Fairfield, Ohio, United States) according to ASTM D882-12 (ASTM D882-12). The films were cut into strips $(1.4 \times 5 \mathrm{~cm})$ using a dual-blade shear cutter (JDC Precision Cutter 10 in., Thwing-Albert Instrument Company, West Berlin, New Jersey, United States) and conditioned for 3 days $(50 \% \mathrm{RH})$. Before testing, thickness of the strips was measured with a digital micrometer to the nearest $0.001 \mathrm{~mm}$. Five thickness measurements were taken on each testing sample at various points, and the mean values were used in mechanical and permeability calculations. Force and distance were recorded during the extension of the strips mounted between the grips at $2.5 \mathrm{~cm} / \mathrm{min}$. until the sample broke. The results are the averages of the five samples. TS and percentage elongation at the point at which the film broke was calculated 
using Eq. 1 and 2.

$$
\begin{aligned}
& \text { Tensile strength }(T S)=\frac{\text { Max force }(N)}{\text { Thickness }(m) \times \text { Width }(m)} \\
& E(\%)=100 \times \frac{d r}{d o}
\end{aligned}
$$

where $E(\%)$ is the percentage of $\mathrm{Eb}, d o$ is the distance onset of gage $(\mathrm{cm})$, and $d r$ is the distance of rupture $(\mathrm{cm})$.

\subsection{Water Vapor Permeability}

Water vapor permeability (WVP) of the films was measured according to the ASTM E96/96M standard test method (ASTM E96/96M). Glass cups with bottle mouth diameters of $10 \mathrm{~mm}$ (depth of $40 \mathrm{~mm}$ and internal diameter of $20 \mathrm{~mm}$ ) were preconditioned at $105^{\circ} \mathrm{C}$ for $24 \mathrm{~h}$ to remove any water. The cups were filled with calcium chloride at half the bottle volume to obtain $0 \% \mathrm{RH}$ in the interior of the glass cup; the preconditioned films were mounted on the bottles with paraffin as a sealant. The cups were placed in a desiccator containing saturated sodium chloride solutions $(75 \%$

relative humidity) at $25^{\circ} \mathrm{C}$. Cup weight with $0.0001 \mathrm{~g}$ accuracy was recorded at $0,5,15,20$, and 24 h. Every measurement were made in triplicate, and WVP was calculated using Eq. 3.

$$
W V P=w / t \times x / \Delta p \times A
$$

where $w / t$ is calculated by linear regression $(\mathrm{R} 2>0.99)$ from water absorbed by the system when steady state was reached, $A$ is the film area exposed to moisture transfer, $x$ is the mean sample thickness, and $\Delta p(\mathrm{kPa})$ is the partial pressure difference through the film calculated with Eq. 4 .

$$
\Delta P=S(R 1-R 2)
$$

where $S$ is the saturated vapor pressure at $25^{\circ} \mathrm{C}(3166 \mathrm{kPa})$ and $R 1$ and $R 2$ are the RHs in the desiccator (0.75) and in the interior of the bottle (0), respectively, expressed in fractions.

\subsection{Light Transmission and Film Transparency}


All films were cut into a rectangular shape and placed in a spectrometer (UV-1650PC, Shimadzu Scientific Instruments, Columbia, Maryland, United States), using air as the reference. The light barrier property of the film samples was measured at wavelengths of $280 \mathrm{~nm}$ (UV) and $660 \mathrm{~nm}$ (visible light) according to the method described by Rhim \& Wang (2014). Three replicates of each sample were tested; results were expressed as percentage transmittance.

\subsection{Thermal Gravimetric Analysis}

TGA of films was conducted with a Perkin-Elmer TGA 7 (Norwalk, Connecticut, United States) in a nitrogen atmosphere. Approximately $5 \mathrm{mg}$ of each sample was weighed into a platinum cup and scanned from $25^{\circ} \mathrm{C}$ to $700{ }^{\circ} \mathrm{C}$ at a heating rate of $10^{\circ} \mathrm{C} \mathrm{min}^{-1}$. Maximum degradation rate was calculated as mass (\%) at peak temperature divided by peak temperature.

\subsection{Statistical Analysis}

Data from the mechanical property evaluation were taken from an average of at least two samples. Data from experiments carried out in duplicate were analyzed using analysis of variance (ANOVA) and least significant difference (LSD) at the 0.05 level according to procedures in the SAS statistical software package (SAS Institute 2005, Cary, North Carolina, United States).

\section{Results and Discussion}

\subsection{Moisture content (MC), appearance, and morphology}

Based on preliminary investigation, $\mathrm{CG}$ at a concentration of $0.5 \%$ was selected to prepare films since any lower concentration could cause complications, such as low and uneven film thickness, and require more energy for water evaporation. A higher concentration of CG could make hydration and homogenization difficult and cause casting issues when making films. At least 
$30 \%$ glycerol was used as a plasticizer since lower glycerol levels resulted in undesirable film brittleness when the film was peeled off the glass. CG films were transparent with a smooth surface via visual measurement, as illustrated in Fig. 1A, and ranged from 0.025 to $0.030 \mathrm{~mm}$ in thickness (the thickness of films were the average of 3 measurements with an electronic micrometer with $0.001 \mathrm{~mm}$ resolution). $\mathrm{MC}$ of the films increased from $18.96 \%$ to $28.23 \%$ as the glycerol content increased from $30 \%$ to $70 \%$ (Table 1), which was in agreement with previous studies that showed that glycerol has water-holding capacity, thereby increasing MC in films (Ghasemlou et al., 2011). A similar study reported that when glycerol content was higher than $10 \%$, psyllium hydrocolloidbased films showed increased $\mathrm{MC}$ since the formation of glycerol-gum and glycerol-water interactions increased the water-holding capacity of films (Ahmadi et al., 2012).

Increased understanding of the mechanism of $\mathrm{CG}$ film formation and visualization of individual components of gum in networks at the molecular level could be advanced by observing film's structures at various length scales. Therefore, in this study, morphology properties of CG and CG films were investigated. Under AFM (Fig. 2), we observed intersecting fibrils, which are believed to be the direct shape of CG, with average diameters of $5 \mathrm{~nm}$ and over micrometers length in $\mathrm{CG}$ solution. The linear structure of $\mathrm{CG}$ was expected to form films with maximum mechanical strength because intermolecular hydrogen bonding causes more compactly aggregate of the polymer chain (Murray, 2000; Labropoulos et al., 2002). The thickness of the films studied in this research was $0.025-0.030 \mathrm{~mm}$, consisting of at least 5000-6000 layers of gum fibrils, with each single fibril of gum having an average diameter of $5 \mathrm{~nm}$. Although CG film showed smooth surfaces under visual estimation, condensed fibrils humps were observed under high resolution microscopy, resulting in rough film surfaces in nanoscale (Fig. 2B).

Film structures with nanoclay were more compact than structures of pure gum films because 
nanoclay served as filler in the crossed matrix of gum fibrils (Figs. 2C and 2D). With 10\% nanoclay (Fig. 2D), fibril humps were nearly invisible in the film because they were submerged by the nanoclay. The interaction of fibril matrix in gum and nanoclay increased the mechanical strength and barrier properties of the film due to the formation of hydrogen bonds with those fibrils, as discussed in the following sections. Although the nanoclay served as the filler for CG film, it did not improve films' surface smoothness (Figs. 1C and 1D). In fact, films with nanoclay demonstrated rougher surfaces than pure gums films as a result of nanoclay aggregation during the film-making process, leading to accumulated humps and rough film surfaces. This finding was in agreement with previous studies of nanoclay/chitosan, poly/chitosan/nanoclay, or carrageenan/locust bean gum/nano films (Mahdavi et al., 2013; Xu et al., 2006; Martins et al., 2013).

\subsection{FTIR analysis}

FTIR absorbance patterns of samples are presented in Fig. 3. Nanoclay exhibited typical bands responsible for stretching vibrations of $\mathrm{O}-\mathrm{H}$ at $3,627 \mathrm{~cm}^{-1}$, stretching vibrations of $\mathrm{C}-\mathrm{H}$ from $\mathrm{CH}_{2}$ and $\mathrm{CH}_{3}$ groups $2,900-2,800 \mathrm{~cm}^{-1}$, respectively, bending vibrations of $\mathrm{O}-\mathrm{H}$ from absorbed water and $\mathrm{C}-\mathrm{H}$ from $\mathrm{CH}_{2}$ bending at $1,640 \mathrm{~cm}^{-1}$ and $1,480 \mathrm{~cm}^{-1}$, respectively, and bending vibrations of Si-O-Si at $800-1,100 \mathrm{~cm}^{-1}$ (Martins et al., 2013; Paluszkiewicz et al., 2011).

A spectra of pure CG powder is also presented (Fig. 3) in order to provide a complete investigation of the gum. A broad and intense band between 3000 and $3600 \mathrm{~cm}^{-1}$ was ascribed to $\mathrm{OH}$ stretching, and the broad band was overlapped to the stretching vibration of $\mathrm{N}-\mathrm{H}$ and $\mathrm{C}-\mathrm{H}$ bond in $-\mathrm{CH}_{2}(2920 \mathrm{~cm}-1)$ and $-\mathrm{CH}_{3}\left(2875 \mathrm{~cm}^{-1}\right)$ groups, respectively (Silva et al., 2012). CG showed specific bands in the range of $1200-800 \mathrm{~cm}^{-1}$, which was dominated by ring vibrations overlapped with stretching vibrations of $\mathrm{C}-\mathrm{OH}$ side groups and $\mathrm{C}-\mathrm{O}-\mathrm{C}$ glycosidic bond vibration 
(Kacurakova et al., 2000). Peaks observed at $1070 \mathrm{~cm}^{-1}$ were assigned to galactose unit: The intensive peak at $1070 \mathrm{~cm}^{-1}$ indicated high galactose unit content (Kacurakova et al., 2000). The peaks around $1151 \mathrm{~cm}^{-1}$ were ascribed to contributions from glycosidic linkages (C-O-C). Similar observations were described in an earlier report in which galactose units with any link type and position were found at approximately $1155 \mathrm{~cm}^{-1}$, xyloglucan was found at $1153 \mathrm{~cm}^{-1}$, and polysaccharides with mannose, arabinose, and rhamnose constituents were found at low frequencies (1051-1039 $\mathrm{cm}^{-1}$ ) (Kacurakova et al., 2000). Although the anomeric region between 800 and $1000 \mathrm{~cm}^{-1}$ was complicated due to peak overlapping, this region provided supplemental information to the above descriptions. According to Kacurakova et al. (2000), peaks at $834 \mathrm{~cm}^{-1}$ and $898 \mathrm{~cm}^{-1}$ were designed for $\alpha$ and $\beta$ glycosidic linkage types of aldopyranoses and furanoid compounds, respectively. The peak at $898 \mathrm{~cm}^{-1}$ was sharper than the peak $834 \mathrm{~cm}^{-1}$, indicating that $\beta$ glycosidic linkage was dominated in CG. Peaks around $1630 \mathrm{~cm}^{-1}$ and $1540 \mathrm{~cm}^{-1}$ were dominated by amide I for $-\mathrm{C}=\mathrm{O}$ stretch and amide II for $-\mathrm{N}-\mathrm{H}$ bend, respectively (Yu et al., 2005). A sharp peak around $1600 \mathrm{~cm}^{-1}$ was detected for $\mathrm{CG}$, which was attributed to carboxylate asymmetrical stretch (Pasqui et al., 2012). Amide I and II uniquely contained C=O, C-N, and N-H from camelina albumin protein ( $\mathrm{Li}$ et al., 2016). Amide I absorption contained contributions primarily from $\mathrm{C}=\mathrm{O}$ stretching vibration $(80 \%)$ with a minor C-N stretching vibration, while amide II absorption was caused by N-H bending vibrations (60\%) and C-N stretching vibrations (40\%) (Jackson \& Mantsch, 1995).

Interactions of gum with glycerol and nanoclay were also investigated. The peak of O-H stretching vibration at $3260 \mathrm{~cm}^{-1}$ on gum shifted to $3255 \mathrm{~cm}^{-1}$ on film with and without nanoclay, indicating that hydrogen bond interaction occurred between CG and the glycerol. The hydrogen bonds between polysaccharide molecules might be broken, and new hydrogen bonds might be 
formed between hydroxyl groups in nanoclay $\left(3627 \mathrm{~cm}^{-1}\right)$ and the $\mathrm{O}-\mathrm{H}$ stretching vibration in glycerol $\left(3260 \mathrm{~cm}^{-1}\right)$ and the polysaccharide molecules as indicated by previous study (Slavutsky et al., 2012).

\subsection{X-ray diffraction}

Crystallinity of the film samples was evaluated using XRD analysis (Fig. 4). The board peaks at $2 \theta=22.13^{\circ}$ and $16^{\circ}$ suggested that $C G$ is an amorphous material. The characteristic diffraction peak of XRD pattern of nano clay was $7.05^{\circ}(2 \theta)$, corresponding to a nanoclay interlayer spacing of $1.25 \mathrm{~nm}$. This peak shifted to lower angle around $4.8^{\circ}(d=1.83 \mathrm{~nm})$ after the nanocomposite formed with the CG matrix. The $d$ spacing of nanoclay was not affected by the nanoclay concentration, but the peak intensity $\left(4.8^{\circ}\right)$ increased as the clay amount increased, indicating that the camelina chains entered into the silicate layers and formed intercalated CG/nanoclay nanocomposite instead of the complete exfloliation structure. The interaction between CG and nanoclay was promoted by hydrogen bonding between carbonyl groups in CG and hydroxyl groups at the silicate layer of nanoclay, as shown in Fig. 3. In addition, the peak $\left(22.13^{\circ}\right)$ from CG broadened with the inclusion of nanoclay, indicating reduced crystallinity of CG film and suggesting that the interaction between two polymers further weaken the CG chain primary structure.

\subsection{Mechanical property}

Mechanical properties of a film determine its durability and ability to be used as a coating to enhance the mechanical integrity of foods. Without plasticizer, CG exhibited poor film-forming ability because it did not show sufficient cohesive strength to remain intact when peeled off the casting glass. Therefore, the data of CG film without plasticizer is not presented in this paper. The effects of glycerol and nanoclay on tensile strength (TS) and elongation at break (Eb) are reported 
in Tables 1 and 2, respectively. Glycerol contents had a positive effect on the Eb and negative effect on the TS of films. In particular, Eb values increased from $8.3 \%$ to $22.47 \%$ and TS values decreased from 56.01 $\mathrm{MPa}$ to $25.89 \mathrm{MPa}$ when glycerol content increased from $30 \%$ to $70 \%$. Glycerol acted as a plasticizer, decreased the molecular weight of the mixture compared to pure camelina gum, and reduced the intermolecular force and increased the mobility of polymer chains in CG, leading to decreased TS and increased $\mathrm{Eb}$ of films. Similar observations of the effects of glycerol on mechanical properties of polysaccharide-based gums have been made in previous studies. TS decreased from 17.75 MPa to 9.44 MPa for chia seed mucilage-based film and Eb values increased from $1.93 \%$ to $15.89 \%$ when glycerol increased from $25 \%$ to $75 \%$ as plasticizer (Dick et al., 2015). Moreover, the presence of glycerol at low concentrations (15\%) showed high tensile strength for starch-based films because strong hydrogen bonds between starch intermolecular dominated the hydrogen bonds between glycerol and starch. A high concentrations (30 and 45\%) of glycerol weakened the intramolecular attraction between the chains in polysaccharides and reinforced the formation of hydrogen bonds between polysaccharides and glycerol, resulting in decreased tensile strength (Sanyang et al., 2015).

Increasing Eb values of plasticized film indicated that glycerol can improve the flexibility and stretchability of films because glycerol enhances the mobility of polymer chains of CG. Because plasticizers disrupt intermolecular hydrogen bonds in CG molecular and cause new hydrogen bonds to form between glycerol and gum, film rigidity was weakened and film deformability and flexibility was strengthened with the addition of glycerol. Film making formula of CG with $50 \%$ of glycerol was selected for further nanoclay modification for it showed balanced mechanical strength and flexibility compared to other formulas.

Incorporation of 2\%-4\% nanoclay can improve the TS of CG film without change of Eb (Table 
2). When nanoclay content was higher than $4 \%$, the CG film reached a plateau of TS and Eb values of the films increased only slightly. Based on previous reports, improved TS of film was attributed to the hydrogen bond-induced interaction between the CG matrix and intercalated nanoclay, which was proved by the XRD data (Fig. 4). Moreover, the organic modifier, methyl dihydroxyethyl hydrogenated tallow (quaternary ammonium salts), had two - $\mathrm{OH}$ groups, which may also have acted as a bridge connecting CG polymer chains and nanoclay layers (Nayak \& Mohanty, 2010). Interfacial affinity between intercalated nanoclay and the CG matrix demonstrated physically cross-linked networks, resulting in significantly improved TS. However, high nanoclay loading levels $(6 \%-10 \%)$ dispersed poorly in CG polymer and contained agglomerates (Fig. 1D) due to the high surface energies of nanoclay (Jang et al., 2010; Xu et al., 2006), therefore, the TS of CG film decreased but not significant. therefore, the TS of CG film decreased but not significant. No distinctive change in the Eb value within a range of $13.52 \%-16.47 \%$ was observed for the ductility of CP film. Similar results have been reported regarding agar/nanoclay nanocomposite films (Rhim, 2011; Rhim \& Wang, 2013).

CG films have comparable mechanical strength (56.01 MPa) to carrageenan gum films (56.5 MPa) with 30\% glycerol (Rhim \& Wang, 2014). However, the mechanical strength of CG films was much stronger than that of the films made from other polysaccharides, such as agar gum (46.36 MPa) with 30\% glycerol (Rhim \& Wang, 2013), guar gum film with 10\% glycerol (42.84 MPa) (Kurt \& Kahyaoglu, 2014), or salep galactomannan films with 10\% glycerol (49.59 MPa) (Kurt \& Kahyaoglu, 2014). Compared to other polysaccharide films that form solutions with $1 \%-2 \%$ solid content, a lower CG loading level $(0.5 \%)$ was sufficient to allow film formation with improved mechanical properties.

\subsection{Water vapor permeability (WVP)}


Barrier properties of packaging films play a key role in eliminating or reducing the water, oxygen, carbon dioxide, aroma exchange between food components and the environment during storage resulting from food metabolism and microbial respiration. The hydrophilic characteristics of polysaccharides cause them to have high affinity with water, thereby promoting the diffusion of water molecules and causing large WVP values of films. As shown in Table 2, nanoclay decreased the WVP of CG films from 0.405 to $0.325 \mathrm{~g} . \mathrm{mm} / \mathrm{h} . \mathrm{m}^{2}$ as the nanoclay loading level increased from $0 \%$ to $10 \%$. This decrease can be attributed to the fact that nanocomposite enhanced the tortuosity of the diffusive path for a penetrant molecule (Mirzadeh et al., 2007) or that the layered structure of the nanoclay increased the path length for water moisture diffusion and retarded the transmission of moisture through the film matrix (Park et al., 2003). Moreover, the methyl tallow bis-2hydroxyethyl ammonium cations contained in organoclay demonstrated increased hydrophobicity (Antoniou et al., 2015) compared to unmodified nanoclay, which also may have contributed to the improved water barrier properties of the nanocomposite film. The MC of CG/nano-based film with $10 \%$ nanoclay decreased to $18.55 \%$ compared to $22.23 \%$ for pure CG gum film. The CG/nanobased films potentially had a more compact structure that allowed less hydroxyl groups of CG chains to connect with water molecules than pure gum-based film.

\subsection{Light transmission}

UV barrier and transparency properties of the films were evaluated by measuring the transmittance of the films at $280 \mathrm{~nm}$ (UV) and $660 \mathrm{~nm}$ (visible), as shown in Fig. 5. The transmission of CG films was $19.55 \%$ and $39.53 \%$ at UV and visible region, respectively. CG typically contains approximately $12 \%$ camelina albumin protein (Li et al., 2016). Protein-based films had a high content of aromatic amino acids that absorbed more UV light (Ramos et al., 2013), potentially contributing to the improvement of film's UV barrier properties but also potentially 
causing decreased visible light transmission and reduced transparency of CG films. The inclusion of nanoclay into the camelina films reduced the transmission of UV and visible light. With 10\% nanoclay, transmittance values decreased to $12.65 \%$ and $28.99 \%$, respectively. The decrease in light transmission could be attributed to the prevention of light passage by the nanoclay dispersed in the polymer matrix. This result suggested that nanoclay could be used in film making for packaged food to retard lipid oxidation, discoloration, formation of off-flavor, and loss of nutrients induced by UV light (Ramos et al., 2013). Transparency is also an important physical property of packaging films. CG film with 6\% nanoclay or higher had reduced transparency (Fig. 5), potentially due to the opaque appearance and aggregation of nanoclay (Kanmani \& Rhim, 2014; Hong \& Rhim, 2008).

\subsection{Thermal properties}

Thermogravimetric analysis was used to evaluate the thermal stability of films in this study. All the films displayed similar behavior with four main stages of thermal degradation in the temperature range of $25-700^{\circ} \mathrm{C}\left(\right.$ Fig. 6). The first stage $\left(50-120^{\circ} \mathrm{C}\right)$ corresponded to the moisture released from the films. The second stage $\left(160-200{ }^{\circ} \mathrm{C}\right)$ was related to the loss of glycerol and structurally bound water (Martin et al., 2012). CG film decomposition was attributed to the third and fourth stage (weight loss of approximately $65 \%$ ), which occurred at $250-290{ }^{\circ} \mathrm{C}$ and $310-$ $350{ }^{\circ} \mathrm{C}$, suggesting two types of chain structures with unique thermal stabilities. The temperatures corresponding to camelina film thermal degradation $\left(\mathrm{T}_{\mathrm{d}}\right)$ and the temperatures of $50 \%$ weight loss $\left(\mathrm{T}_{50}\right)$ are shown in Table $2 . \mathrm{T}_{\mathrm{d}}$ and $\mathrm{T}_{50}$ increased from $268^{\circ} \mathrm{C}$ to $273{ }^{\circ} \mathrm{C}$ and from $275^{\circ} \mathrm{C}$ to $282^{\circ} \mathrm{C}$, respectively, as the nanoclay increased from $0 \%$ to $8 \%$ and then levelled off at $10 \%$. Thermal stability of CG film increased after formation of the nanocomposite with nanoclay. However, nanoclay levels higher than $8 \%$ may have the nanoclay aggregation and steric hindrance effects on 
the interaction with $\mathrm{CG}$, leading to limited thermal stability enhancement.

\section{Conclusions}

CG-based films demonstrated mechanical strength comparable to carrageenan gum film and was stronger than other gums, including agar gum, guar gum, and salep galactomannan. A low CG concentration $(0.5 \%)$ was required in order for CG film to form with good mechanical properties compared to other polysaccharide gums $(1 \%-2 \%)$. FTIR and XRD results revealed that the intercalation structure of nanoclay in CG polymer matrix was formed by the hydrogen bonding interaction between $\mathrm{CG}$ and nanoclay, contributing improved mechanical and barrier properties of CG/nanoclay based films. Increased nanoclay loading levels $(6 \%-10 \%)$ did not significantly improve mechanical strength due to poor dispersion and the presence of agglomerates of nanoclay. Nanoclay improved WVP and UV barrier properties but slightly decreased film transparency. CG/nanoclay showed great potential application as environmentally friendly food packaging materials.

\section{Acknowledgments}

This work was supported by Biomass Research and Development Initiative Program with grant

number of 2012-10006-20230 from the U.S. Department of Agriculture National Institute of Food and Agriculture. 


\section{References}

Ahmadi, R., Kalbasi-Ashtari, A., Oromiehie, A., Yarmand, M., \& Jahandideh, F. (2012). Development and characterization of a novel biodegradable edible film obtained from psyllium seed (Plantago ovata Forsk). Journal of Food Engineering, 109, 745-751.

Alexandre, M., \& Dubois, P. (2000). Polymer-layered silicate nanocomposites: preparation, properties and use of new class of materials. Materials Science and Engineering, 28, 1-63.

Antoniou, J., Liu, F., Majeed, H., \& Zhong, F. (2015). Characterization of tara gum edible films incorporated with bulk chitosan and chitosan nanoparticles: A comparative study. Food Hydrocolloids, 44, 309-319.

ASTM D882-12. Standard test method for tensile properties of thin plastic sheeting. Current edition approved Aug. 1, 2012. Published September 2012. Originally approved in 1946. Last previous edition approved in 2010 as D882 - 10. DOI: 10.1520/D0882-12.

ASTM E96/E96M. Standard test methods for water vapor transmission of materials. Current edition approved Oct. 15, 2014. Published January 2015. Originally approved in 1953. Last previous edition approved in 2013 as E96- 13. DOI: 10.1520/E0096_E0096M-14.

Dick, M., Costa, T., Gomaa, A., Subirade, M., Rios, A., \& Flores, S. H. (2015). Edible film production form chia seed mucilage: effect of glycerol concentration its physicochemical and mechanical properties. Carbohydrate Polymers, 130, 198-205.

Embuscado, M., \& Huber, K. (2009). Edible Films and Coatings for Food Applications. New York: Springer, (Chapter 1).

Ghasemlou, M., Khodaiyan, F., \& Oromiehie, A. (2011). Physical, mechanical, barrier, and thermal properties of polyol-plasticized biodegradable edible film made from kefiran. Carbohydrate Polymers, 84(1), 477-483.

Gontard, N., Guilbert, S., \& Cuq, J. L. (1993) Water and glycerol as plasticizers affect mechanical and water vapour barrier properties of an edible wheat gluten film. Journal of Food Science, 58 (1), 206-211.

Hong, S. I., Rhim, J. W. (2008). Antimicrobial activity of organically modified nano-clays. Journal of Nanoscience and Nanotechnology, 8, 5818-5824.

Jackson, M., Mantsch, H. (1995). The use and misuse of FTIR spectroscopy in the determination of protein structure. Critical Reviews in Biochemistry and Molecular Biology, 30 (2), 95-120.

Jang, S., Lim, G., \& Song, K. (2010). Original article: Use of nano-clay (Cloisite Na+) improves tensile strength and vapour permeability in agar rich red algae (Gelidium corneum)-gelatin composite films. International Journal of Food Science \& Technology, 45(9), 1883-1888.

Kacurakova, M., Capek, P., Sasinkova, V., Wellner, N., \& Ebringerova, A. (2000). FT-IR study of plant cell wall model compounds: pectic polysaccharides and hemicelluloses. Carbohydrate Polymer, 43, 195-203.

Kanmani, P., \& Rhim, J. W. (2014). Physical, mechanical and antimicrobial properties of gelatin based active nanocomposite films containing AgNPs and nanoclay. Food Hydrocolloids, 35, 644-652.

Kurt, A., Kahyaoglu, T. (2014). Characterization of a new biodegradable edible film made from salep glucomannan. Carbohydrate Polymers, 104, 50-58. 
Labropoulos, K. C., Niesz, D. E., Danforth, S. C., \& Kevrekidis, P. G. (2002). Dynamic rheology of agar gels: theory and experiment. Part I. Development of a rheological model. Carbohydrate Polymers, 50, 393-406.

Li, N., Qi, G., Sun, X., \& Wang, D. (2016). Characterization of gum isolated from camelina seed. Industrial Crops and Products, 83, 268-274.

Mahdavi, H., Mirzadeh, H., Zohuriaan-Mehr, M., \& Talebnezhad, F. (2013). Poly (vinyl alcohol)/chitosan/clay nanocomposite films. Journal of American Science, 9(8), 203-214.

Martins, J. T., Bourbon, A. I., Pinheiro, A. C., Souza, B. W. S., Cerqueira, M. A., \& Vicente, A. A. (2013). Biocomposite films based on $\kappa$-carrageenan/locust bean gum blends and clays: physical and antimicrobial properties. Food Bioprocess Technology, 6, 2081-2092.

Mirzadeh, A., \& Kokabi, M. (2007). The effect of composition and draw-down ratio on morphology and oxygen permeability of polypropylene nanocomposite blown films. European Polymer Journal, $43(9), 3757-3765$.

Murray, J. C. F. (2000). Cellulosics. In G. O. Phillips, P. A. Williams (Eds.), Handbook of Hydrocolloids (pp. 219-229). Cambridge: Woodhead Publishing Ltd.

Nayak, S. K., \& Mohanty, S. (2010). Poly (trimethylene) terephthalate/m-LLDPE blend nanocomposites, evaluation of mechanical, thermal and morphological behavior. Materials Science and Engineering A, 527 (3), 574-583.

Paluszkiewicz, C., Stodolak, E., Hasik, M., \& Blazewicz, M. (2011). FT-IR study of montmorillonitechitosan nanocomposite materials. Spectrochimica Acta Part A: Molecular and Biomolecular Spectroscopy, 79(4), 784-788.

Park, H. M., Lee, W. K., Park, C. Y., Cho, W. J. \& Ha, C. S. (2003). Environmentally friendly polymer hybrids part I. mechanical, thermal, and barrier properties of thermoplastic starch / clay nanocomposites. Journal of Materials Science, 38, 909-915.

Pasqui, D., Cagna, M.D., \& Barbucci, R. (2012). Polysaccharide-based hydrogels: the key role of water in affecting mechanical properties. Polymer, 4, 1517-1534.

Phan, T. D., Debeaufort, F., Peroval, C., Despre, D., Courthaudon, J. L., \& Voilley, A. (2002). Arabinoxylan-lipid-based edible films ad coating. 3. Influence of drying temperature on film structure and functional properties. Journal of Agricultural and Food Chemistry, 50 (8), 2423-2428.

Ramos, O. L., Reinas, I., Silva, S. I., Fernandes, J. C., Cerqueira, M. A., \& Pereira, R. N. (2013). Effect of whey protein purity and glycerol contant upon properties of edible films manufactured therefrom. Food Hydrocolloids, 30, 110-122.

Rhim, J. W. (2011). Effect of clay contents on mechanical and water vapor barrier properties of agarbased nanocomposite films. Carbohydrate Polymers, 86, 691-699.

Rhim, J. W., \& Wang, L. F. (2014). Preparation and characterization of carrageenan-based nanocomposite films reinforced with clay mineral and silver nanoparticles. Applied Clay Science, 97-98, 174-181.

Rhim, J. W., \& Wang, L. F. 2013. Mechanical and water barrier properties of agar/-carrageenan/konjac glucomannan ternary blend biohydrogel films. Carbohydrate Polymers, 96, 71-78.

Rhim, J. W., Lee, B. B., Hong, S. I. (2011). Preparation and characterization of agar/clay nanocomposite films: the effect of clay type. Journal of Food Science. 76, 40-48.

Ruiz-Hitzky, E., Aranda, P., Darder, M., \& Rytwo, G. (2010). Hybridmaterials based on clays for environmental and biomedical applications. Journal of Material Chemistry, 20(42), 9306-9321. 
Sanyang, M., Sapuan, S., Jawaid, M., Ishak, M., \& Sshari, J. (2015). Effect of plasticizer type and concentration on tensile, thermal and barrier properties of biodegradable films based on sugar palm (Arenga pinnata) starch. Polymers, 7(6), 1106-1124.

Silva, S. M. L, Braga, C. R. C., Fook, M. V. L., Raposo, C. M. O., Carvalho, L. H., \& Canedo, E. L. (2012). In T. Theophile (Eds), Infrared spectroscopy-materials science, engineering and technology (pp. 43-62). Intech.

Slavutsky, A., Bertuzzi, M., \& Armada, M. (2012). Water barrier properties of starch-clay nanocomposite films. Brazilian Journal of Food Technology, 15(3), 208-218.

Sothornvit, R., \& Krochta J. M. (2000). Oxygen permeability and mechanical properties of films from hydrolyzed whey protein. Journal of Agricultural and Food Chemistry, 48, 3913-3916.

Talens, P., Chiralt, M. J., \& Fabra A. (2010). Biotechnology in Agriculture, Industry and Medicine: Edible Polysaccharide Films and Coatings. Nova Science Publisher.

Yu, P., Mckinnon, J.J., Soita, H.W., Christensen, C.R., \& Christensen, D.A. (2005). Use of synchrotronbased FTIR microspectroscopy to determine protein secondary structures of raw and heat-treated brown and golden flax seeds: a novel approach. Canadian Journal of Animal Science, 85, 437-448.

Xu, Y., Ren, X., \& Hanna, M. A. (2006). Chitosan / clay nanocomposite film preparation and characterization. Journal of Applied Polymer Science, 99, 1684-1691. 
Table 1. Effects of glycerol contents on mechanical properties of CG-based films.

\begin{tabular}{cccc}
\hline Glycerol (wt, \%) & $\begin{array}{c}\text { Moisture } \\
\text { content }(\%)\end{array}$ & $\begin{array}{c}\text { Tensile strength } \\
(\mathrm{MPa})\end{array}$ & $\begin{array}{c}\text { Elongation at break } \\
(\%)\end{array}$ \\
\hline $30 \%$ & $18.96 \mathrm{a}^{1}$ & $56.01 \mathrm{a}^{1}$ & $8.30 \mathrm{a}^{1}$ \\
$40 \%$ & $22.96 \mathrm{~b}$ & $50.11 \mathrm{~b}$ & $10.67 \mathrm{~b}$ \\
$50 \%$ & $22.23 \mathrm{c}$ & $42.38 \mathrm{c}$ & $14.07 \mathrm{c}$ \\
$60 \%$ & $28.24 \mathrm{~d}$ & $34.17 \mathrm{~d}$ & $17.60 \mathrm{~d}$ \\
$70 \%$ & $28.23 \mathrm{~d}$ & $25.89 \mathrm{e}$ & $22.47 \mathrm{e}$ \\
\hline
\end{tabular}

${ }^{1}$ Means in the same column followed by different letters are significantly different at $\mathrm{p}<0.05$. 
Table 2. Moisture content, water vapor permeability, and mechanical and thermal properties of CG and CG-based films.

\begin{tabular}{ccccccc}
\hline $\begin{array}{c}\text { Nano- } \\
\text { clay } \\
(\mathrm{wt}, \%)\end{array}$ & $\begin{array}{c}\mathrm{MC} \\
(\%)\end{array}$ & $\begin{array}{c}\text { WVP } \\
\left(\mathrm{g} . \mathrm{mm} / \mathrm{h}^{2} \mathrm{~m}^{2} . \mathrm{Mpa}\right)\end{array}$ & $\begin{array}{c}\text { Tensile } \\
\text { strength } \\
(\mathrm{MPa})\end{array}$ & $\begin{array}{c}\text { Elongation } \\
\text { at break } \\
(\%)\end{array}$ & $\mathrm{T}_{50}\left({ }^{\circ} \mathrm{C}\right)^{2}$ & $\mathrm{~T}_{\mathrm{d}}\left({ }^{\circ} \mathrm{C}\right)^{3}$ \\
\hline $0 \%$ & $22.23 \mathrm{a}^{1}$ & $0.405 \mathrm{ab}^{1}$ & $43.23 \mathrm{a}^{1}$ & $14.07 \mathrm{a}^{1}$ & 275.02 & 268.06 \\
$2 \%$ & $21.18 \mathrm{~b}$ & $0.409 \mathrm{a}$ & $52.36 \mathrm{~b}$ & $14.01 \mathrm{a}$ & & \\
$4 \%$ & $21.32 \mathrm{~b}$ & $0.396 \mathrm{bc}$ & $54.55 \mathrm{~b}$ & $13.52 \mathrm{a}$ & 279.26 & 270.47 \\
$6 \%$ & $19.47 \mathrm{c}$ & $0.402 \mathrm{ac}$ & $53.96 \mathrm{~b}$ & $13.98 \mathrm{a}$ & 281.01 & 270.08 \\
$8 \%$ & $18.20 \mathrm{e}$ & $0.337 \mathrm{~d}$ & $51.63 \mathrm{~b}$ & $16.47 \mathrm{~b}$ & 282.84 & 273.05 \\
$10 \%$ & $18.55 \mathrm{~d}$ & $0.325 \mathrm{e}$ & $51.50 \mathrm{~b}$ & $16.25 \mathrm{~b}$ & 281.12 & 273.55 \\
\hline
\end{tabular}

${ }^{1}$ Means in the same column followed by different letters are significantly different at $\mathrm{p}<0.05$.

${ }^{2}$ The temperature of $50 \%$ weight loss of films.

${ }^{3}$ The residue at $450{ }^{\circ} \mathrm{C}$ and decomposition temperature of films. 


\section{FIGURE CAPTION:}

Figure 1. SEM images of CG-based films

Figure 2. AFM topography images of CG and CG-based films

Figure 3. FTIR spectra of CG and CG-based films

Figure 4. XRD pattern of CG films

Figure 5. Light transmission of CG-based films

Figure 6. TGA thermograms of CG-based films 

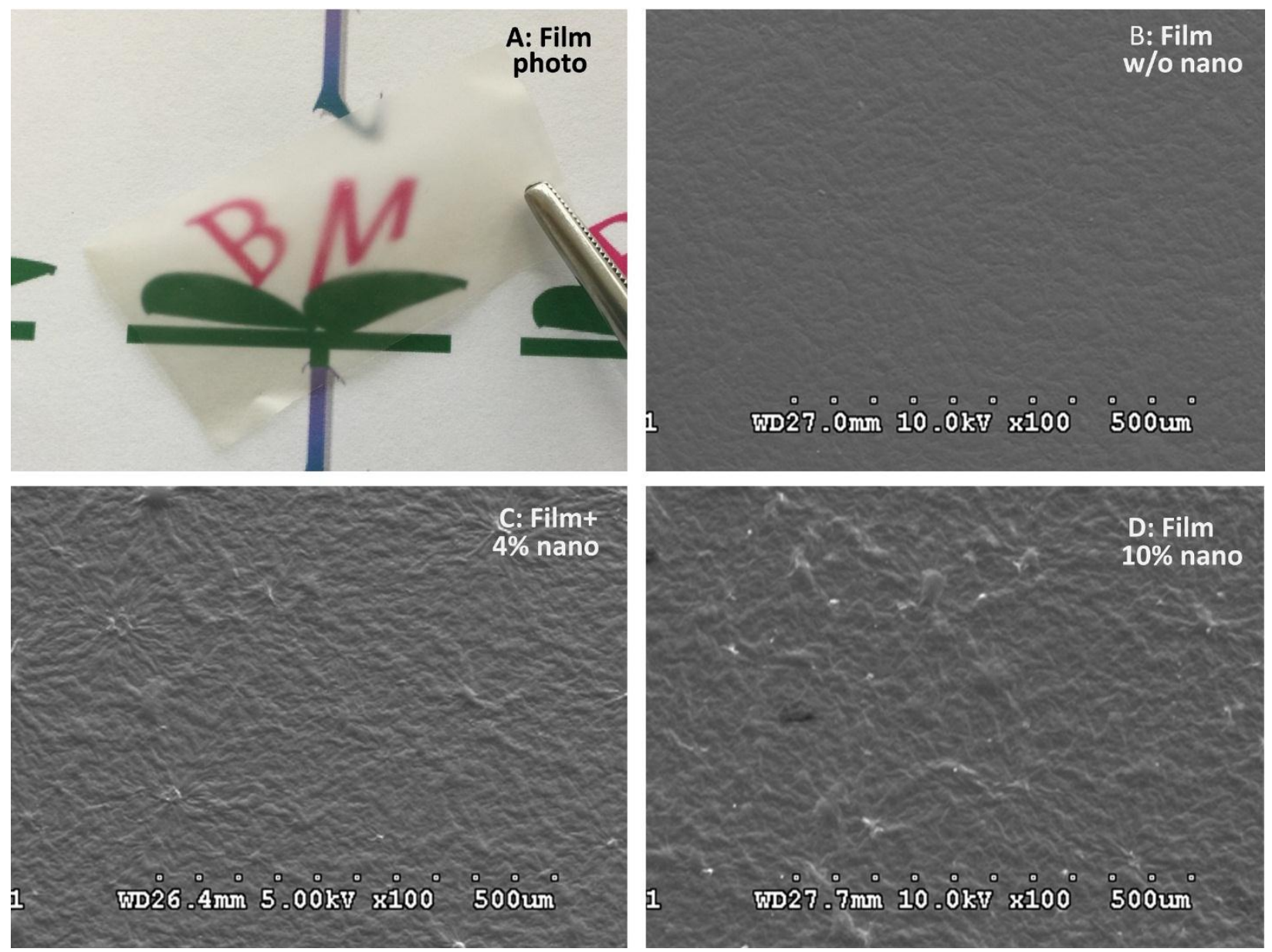

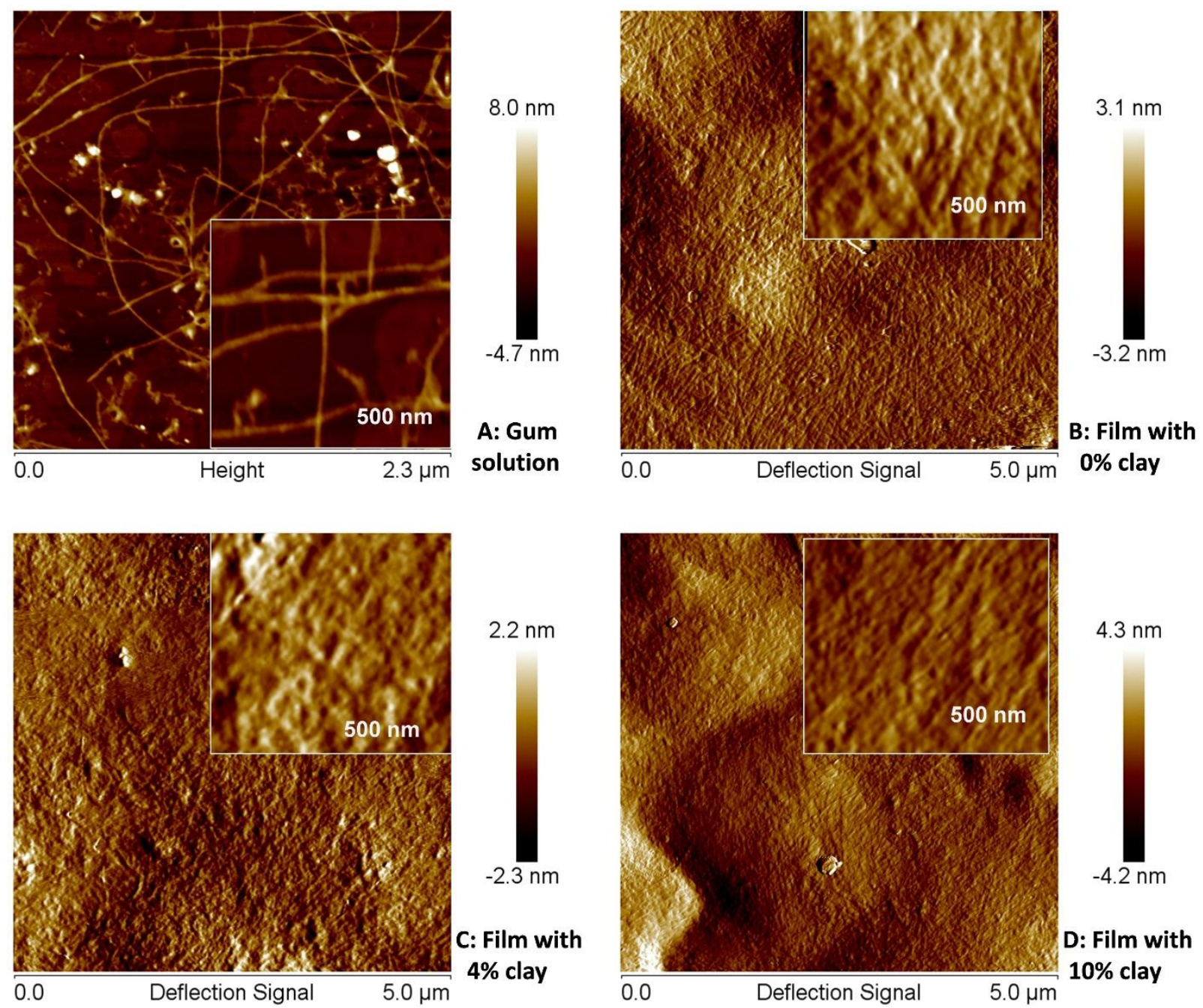


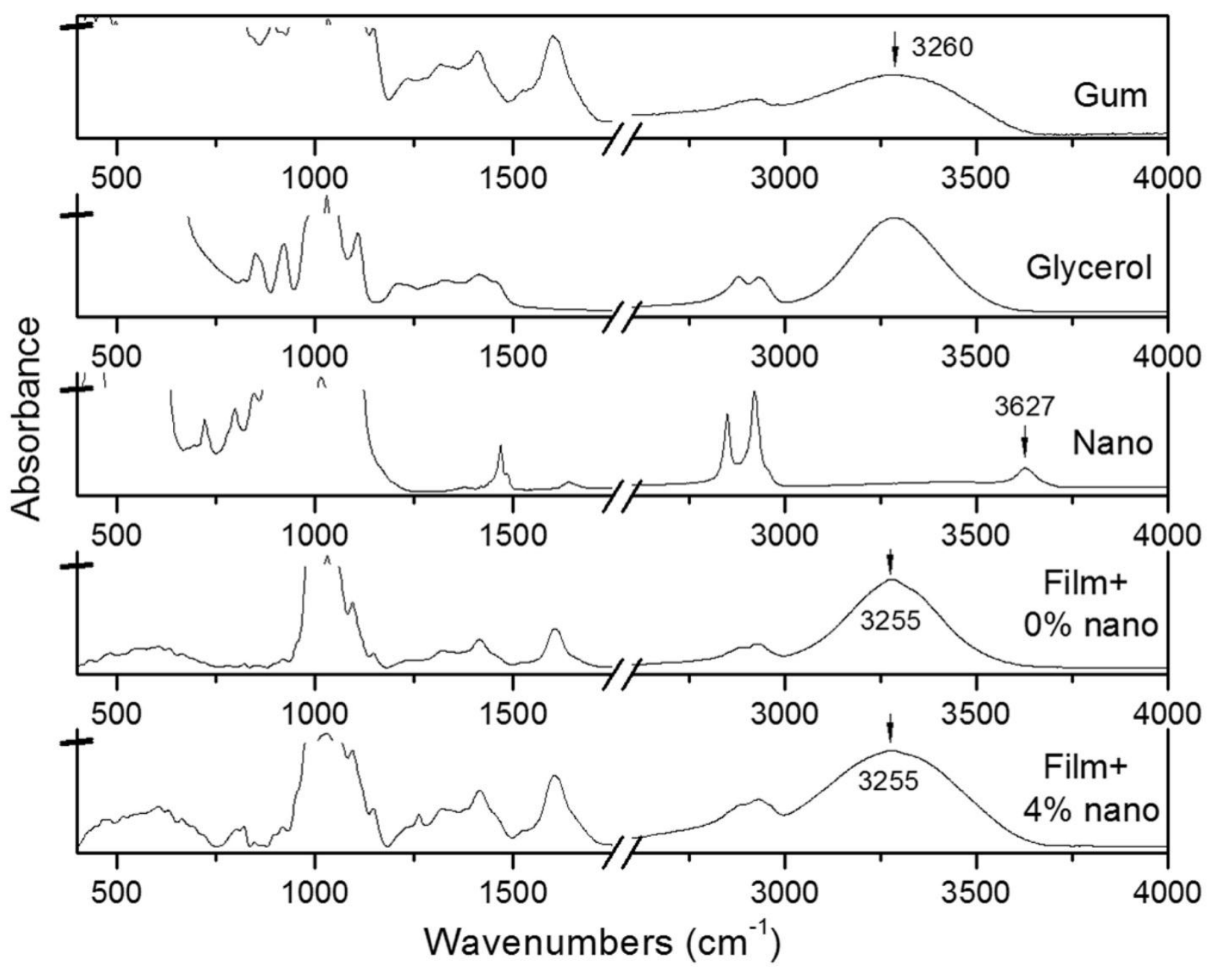




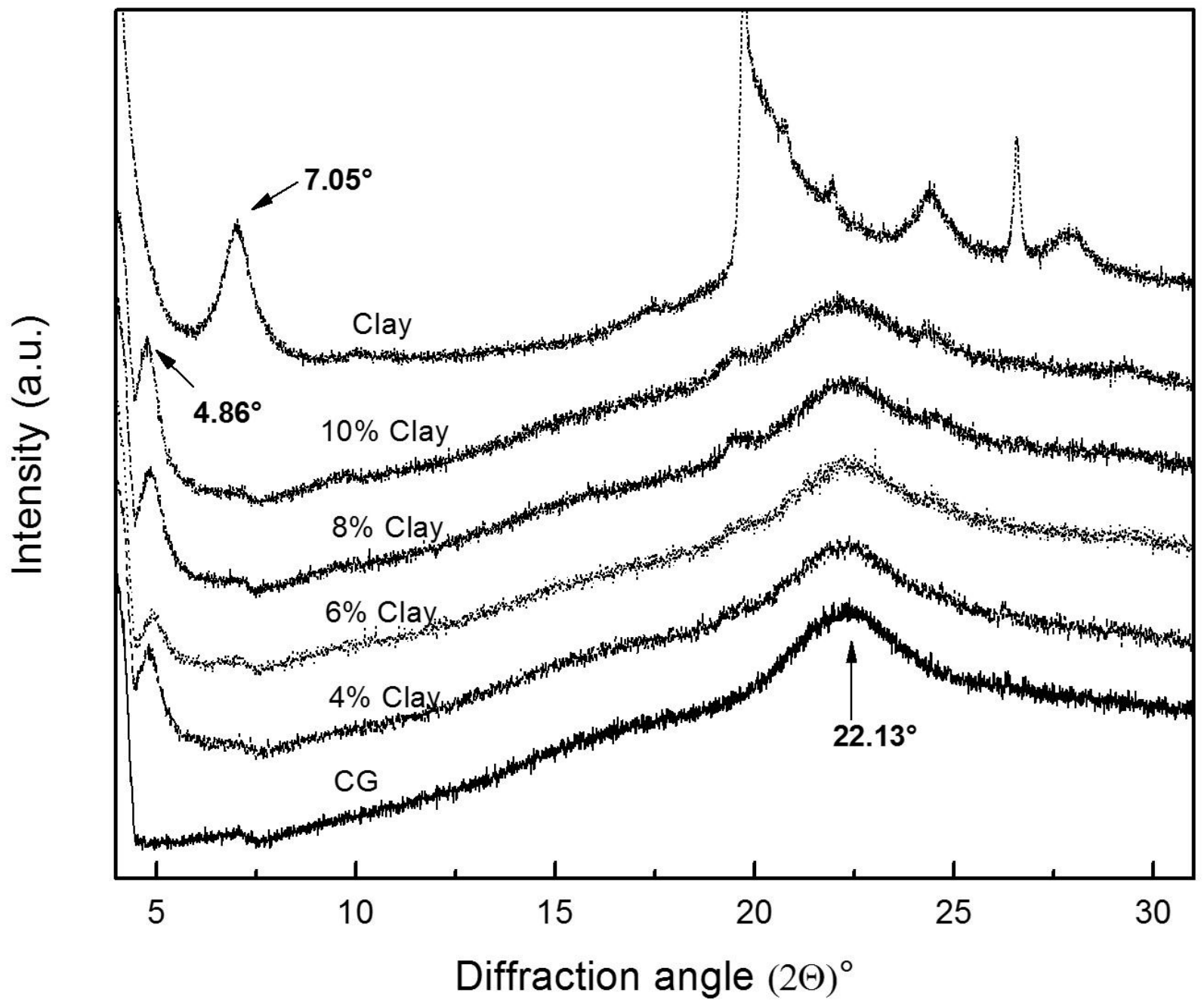




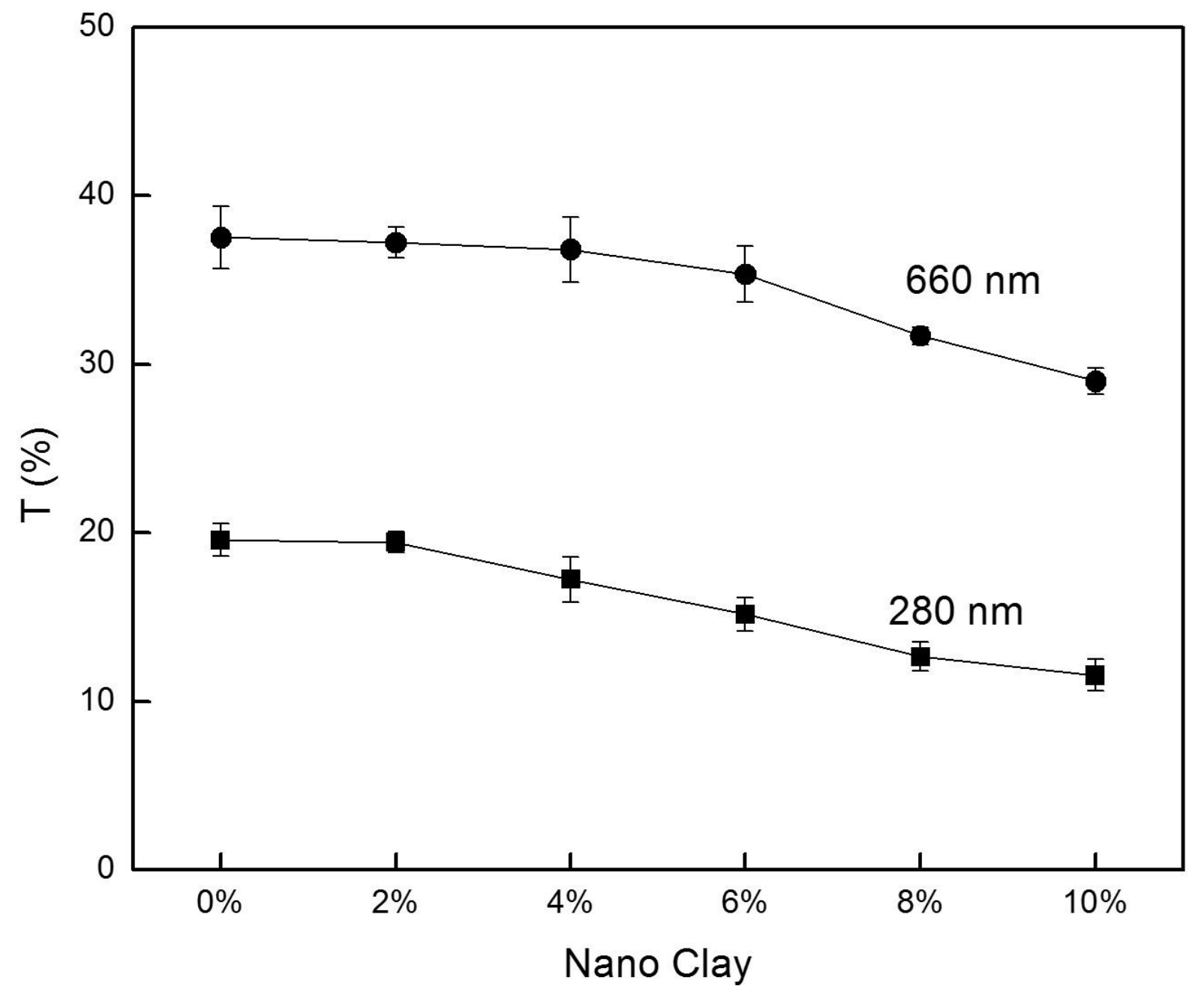




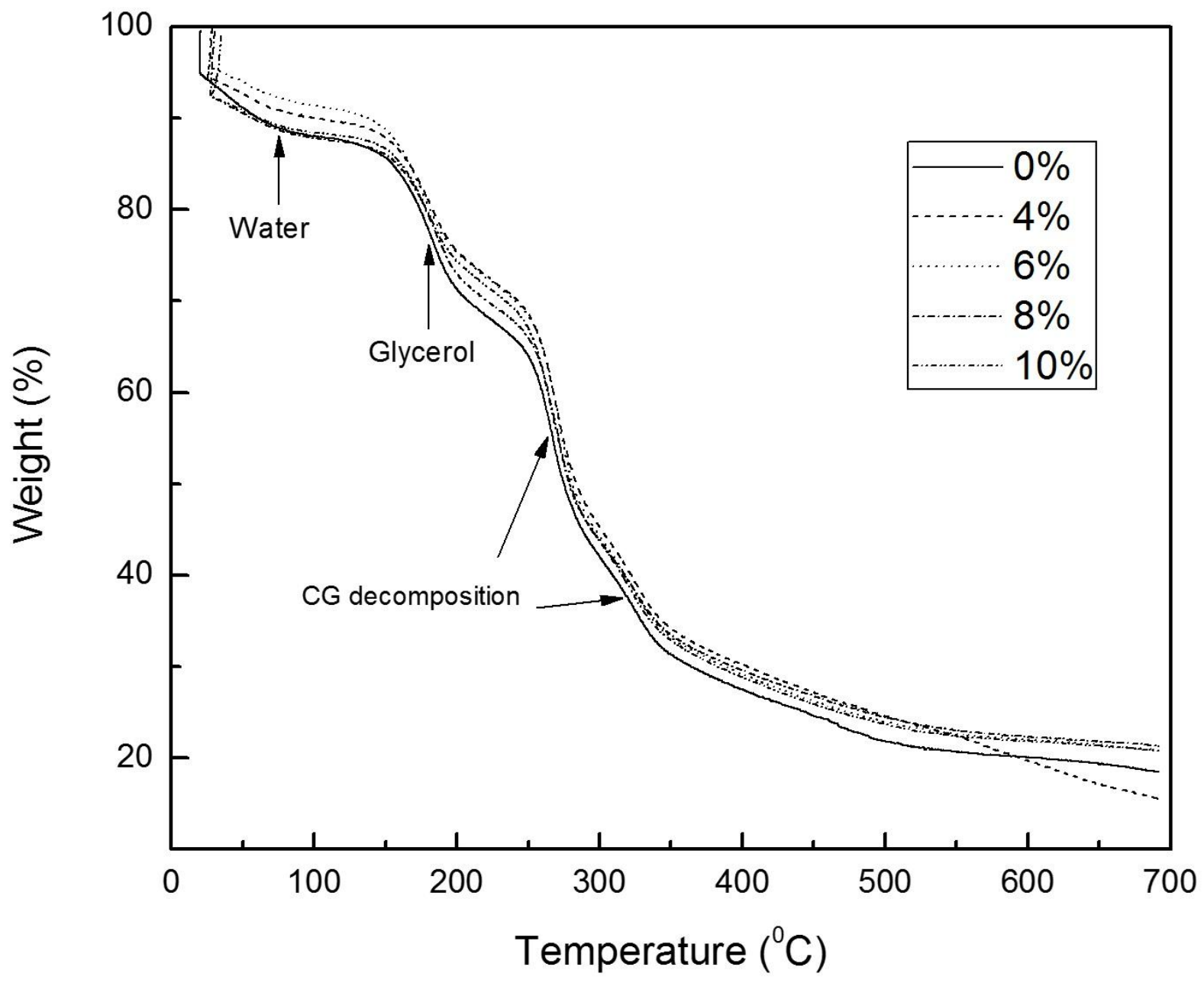

